\title{
O princípio educativo em Gramsci: contribuições ao ensino de filosofia
}

\author{
The educational principle in Gramsci: contributions to the teaching of \\ philosophy
}

\section{El principio educativo en Gramsci: contribuciones a la enseñanza de la filosofía}

\author{
Gabriela da Nóbrega Carreiro" \\ Universidade Federal da Paraíba, Programa de Pós-graduação em Educação, Pesquisadora. \\ https://orcid.org/0000-0001-5559-9901 \\ Tânia Rodrigues Palhano² \\ Universidade Federal da Paraíba, Departamento de Fundamentação da Educação, \\ Professora. \\ https://orcid.org/0000-0003-3573-6889 \\ Maria das Graças de Almeida Baptista ${ }^{3}$ \\ Universidade Federal da Paraiba, Departamento de Fundamentação da Educação, Professora. \\ https://orcid.org/0000-0003-1084-4269
}

Resumo: Esse artigo tem como objetivo apontar a filosofia da práxis como elo fundante entre o princípio pedagógico de Antonio Gramsci e a prática do ensino de filosofia. Nesse processo, situamos o ensino de filosofia no contexto educacional e escolar brasileiro e propomos como via dialógica, vincular a prática de ensino de filosofia à contribuição de uma perspectiva filosófica-educacional fundamentada no pensamento gramsciano, recorrendo às concepções de educação, de escola e ensino presentes nas obras do autor. Destacamos que a filosofia da práxis é o elo fundante entre o princípio pedagógico de Gramsci e a prática do ensino de filosofia; o que pressupõe a correlação dialética e necessária da teoria e da prática, unificando e viabilizando um caminho mais crítico para o processo de formação de uma nova cultura com vistas a concepções do mundo mais críticas e atuantes; o que inclui um projeto político que considere a escola enquanto instrumento ideológico da superestrutura. $A$ investigação, de abordagem qualitativa, se constitui em uma pesquisa de revisão bibliográfica das contribuições da teoria gramsciana para o ensino de filosofia, consideradas enquanto concepção ontológica do sujeito

Mestre e doutoranda em Educação pela Universidade Federal da Paraiba.

2 Pós-doutora em Educação pela Universidade Estadual de Campinas; Doutora e Mestre em Educação pela Universidade Federal da Paraiba.

3 Pós-doutora em Educação pela Universidade Estadual de Campinas; Doutora e Mestre em Educação pela Universidade Federal da Paraiba. 
professor, e enquanto conteúdo curricular que compõe a história da filosofia. Ambas abordagens acionam o campo das ideologias, seja enquanto concepção de mundo do docente que atua nessa área seja enquanto campo conceitual da história da filosofia. Nesse sentido, a filosofia da práxis assume o compromisso de comprometer-se na reelaboração e socialização das verdades já existentes, que até então estão restritas à determinados grupos e a uma formação eminentemente teórica.

Palavras-chave: Ensino de Filosofia. Práxis. Princípio educativo.

Abstract: This article aims to point out the philosophy of praxis as a founding link between the pedagogical principle of Antonio Gramsci and the practice of teaching philosophy. In this process, we place the teaching of philosophy in the Brazilian educational and school context and propose, as a dialogic way, to link the practice of teaching philosophy to the contribution of a philosophical-educational perspective based on Gramscian thinking, using the concepts of education, school and teaching present in the author's works. We emphasize that the philosophy of praxis is the founding link between Gramscis pedagogical principle and the practice of teaching philosophy; what presupposes the dialectical and necessary correlation of theory and practice, unifying and making possible a more critical path for the process of forming a new culture with a view to more critical and active worldviews; which includes a political project that considers the school as an ideological instrument of the superstructure. The investigation, with a qualitative approach, constitutes a research of bibliographic review of the contributions of gramscian theory to the teaching of philosophy, considered as an ontological conception of the teacher subject and as curricular content that composes the history of philosophy. Both approaches trigger the field of ideologies, either as a conception of the world of the teacher who works in this area, or as a conceptual field of the history of philosophy. In this sense, the philosophy of praxis is committed to commit itself to the re-elaboration and socialization of the existing truths, which until then were restricted to certain groups and to an eminently theoretical formation.

Keywords: Teaching Philosophy. Praxis. Educational Principle.

Resumen: Este artículo tiene como objetivo señalar la filosofia de la praxis como un vínculo fundamental entre el principio pedagógico de Antonio Gramsci y la práctica de la enseñanza de la filosofía. En este proceso, ubicamos la enseñanza de la filosofía en el contexto educativo y escolar brasileño y proponemos, como una forma dialógica, vincular la práctica de la filosofía a la contribución de una perspectiva filosóficoeducativa basada en el pensamiento Gramsciano, utilizando los conceptos de educación, escuela y enseñanza. presente en las obras del autor. Hacemos hincapié en que la filosofía de la praxis es el vínculo fundamental entre el principio pedagógico de Gramsci y la práctica de la enseñanza de la filosofía; lo que presupone la correlación dialéctica y necesaria de la teoría y la práctica, unificando y haciendo posible un camino más crítico para el proceso de formar una nueva cultura con vistas a visiones del mundo más críticas y activas; que incluye un proyecto político que considera a la escuela como un instrumento ideológico de la superestructura. La investigación, con un enfoque cualitativo, constituye una investigación de revisión bibliográfica de los aportes de la teoría gramsciana a la enseñanza de la filosofía, considerada como una concepción ontológica de la asignatura docente, y como contenido curricular que compone la historia de la filosofía. Ambos enfoques desencadenan el campo de las ideologías, ya sea como una 
concepción del mundo del maestro que trabaja en esta área, o como un campo conceptual de la historia de la filosofía. En este sentido, la filosofia de la praxis se compromete a comprometerse a la reelaboración y socialización de las verdades existentes, que hasta entonces estaban restringidas a ciertos grupos y a una formación eminentemente teórica.

Palabras llaves: Enseñanza de Filosofia. Práxis. Principio educativo.

Recebido em 24 de julho de 2020 Aceito em 25 de março de 2021

\section{INTRODUÇÃO}

0 ensino de filosofia no contexto educacional e escolar brasileiro recorrentemente é posto à prova. Sua necessidade/utilidade enquanto área de formação, campo de conhecimento e componente curricular no ensino médio vem continuamente consolidando-se nos centros universitários como também nas escolas de educação básica.

A associação da teoria e da prática no ensino de filosofia pressupõe a filosofia da práxis com base no princípio pedagógico de Gramsci, com mira à unificação e viabilização de um caminho coeso no processo de formação de uma nova cultura, com vistas às concepções do mundo mais críticas e atuantes.

Levando em conta o diálogo entre a tradição filosófica e a prática de ensino de Filosofia faz-se necessário um deslocamento epistêmico e filosófico, o que pode ser rememorado na máxima marxiana expressa na Tese 1 , em que os filósofos se limitavam a interpretação, fazendo-se assim necessária a ação prática e objetiva de intervenção no mundo (MARX; ENGELS, 2007).

Desse modo, com a provocação que esta tese propõe para a história da filosofia, propomos uma incursão sobre o pensamento educacional de Gramsci provocando diálogos entorno do ensino da filosofia levando em conta as reformas educacionais que alteram sua realidade na educação básica e sugerindo reflexões mobilizadas em torno da formação educacional gramsciana.

A investigação com o propósito metodológico da abordagem qualitativa, se constitui em uma pesquisa de revisão bibliográfica das contribuições da teoria gramsciana para o ensino de filosofia, consideradas enquanto concepção ontológica do sujeito professor, e enquanto conteúdo curricular que compõe a história da filosofia. 


\section{ENSINO DE FILOSOFIA EM REFORMAS EDUCACIONAIS}

Pesquisar sobre o ensino de filosofia no contexto educacional atual demanda uma atenção pungente aos impasses que situam esta disciplina na história do currículo escolar, de tal forma que ao propormos uma possibilidade de contribuição de uma perspectiva filosóficaeducacional, nesse caso a gramsciana, carecemos de antemão de analisarmos historicamente o processo de culminância que resulta na realidade dessa área de conhecimento nos tempos de hoje.

Com a promulgação da primeira Lei de Diretrizes e Bases da Educação (Lei 4.024 de 1961), o ensino de filosofia inicia a derrocada que deslegitimaria e, consequentemente, reiteraria a desobrigação da presença dessa disciplina no currículo escolar (BRASIL, 1962). Com o acirramento das reformas instauradas com ○ Estado Militar, a educação nacional novamente volta a ser analisada e tem seus documentos basilares reformulados na Lei 5.692 de 1971, o que edificará uma nova perspectiva educacional, levando em conta a rígida reformulação curricular e a implementação de novas disciplinas - por exemplo Educação Moral e Cívica - e exclusão de outras, tais como filosofia e sociologia (BRASIL, 1971). É certo que o início da desobrigação da filosofia iniciou-se com a Lei 4.024/61, mas reiteramos que com a perspectiva educacional difundida no período da Ditadura Civil-Militar, disciplinas como filosofia e sociologia não poderiam continuar nos currículos escolares.

Dessa maneira, com a promulgação da primeira LDB e com a reforma educacional em 1971, o ensino de filosofia em âmbito escolar deixa de existir. Esse (des)caminho iniciase com a Lei 4.024/61, efetiva-se com a Lei 5.692/71 e perdura até o ano de 1996, quando é formulada e sancionada a nova Lei de Diretrizes e Bases para a educação nacional. Passaram-se 25 anos para que, em uma legislação de âmbito nacional, proferisse acerca da necessidade do acesso aos conhecimentos específicos da Filosofia. Uma 'meia vitória', quando levamos em conta que as reformas educacionais anteriores sequer chegaram a utilizar, ou mesmo incluir, em seus textos o termo filosofia.

Com a LDB de 1996 (Lei 9.394/96), temos alusão a uma possibilidade de reinserção da filosofia para o Ensino Médio, através de um único artigo (Art.: 36) que versava sobre a necessidade de os discentes acessarem os conhecimentos de filosofia e sociologia, vinculando tais conhecimentos ao exercício da cidadania (BRASIL, 1996). Mesmo que consideremos significativo, tal artigo e lei não garantiriam a existência dessa disciplina como componente curricular, ficando a critério das instituições incluírem ou não esse ensino. Somente em 2008 , com a promulgação da Lei 11.682, esta disciplina, assim como a sociologia, retorna com caráter obrigatório aos currículos da Educação Básica, sendo componentes específicos para os três anos do Ensino Médio (BRASIL, 2008). 
Vale ressaltar que o texto da Base Nacional Comum Curricular (BNCC), referente à etapa do Ensino Médio, homologado pelo MEC em 14 de dezembro de 2018, com um modelo de "currículo único, nacional e obrigatório" composto por itinerários formativos, que organizados em arranjos curriculares pautados na "prescrição detalhada de competências e habilidades", limita o espaço disciplinar das ciências humanas e sociais reduzindo as disciplinas obrigatórias em três (matemática, português, e inglês) e introduzindo a "modalidade de estudos e práticas em substituição às disciplinas de Sociologia, Filosofia, Artes e Educação Física." (DUARTE et al., 2020, p. 8).

Passados mais de dez anos da implementação da Lei 11.684/08, podemos observar que, mesmo legitimada e legalizada naquele momento, e ainda presente em alguns currículos escolares, a disciplina de filosofia na educação básica percorre um caminho para consolidarse na cultura escolar e na sociedade, tendo em vista as perspectivas utilitaristas enfatizadas nas novas concepções de formação escolar, primordialmente no Ensino Médio.

\section{EDUCAÇÃO E CONCEPÇÃO DO MUNDO EM GRAMSCI}

A questão educacional assume centralidade na teoria gramsciana, pontuada enquanto aprofundamento e enriquecimento para a teoria marxista. Gramsci, como autor da tradição filosófica denominada Materialismo Histórico Dialético, tem como pressupostos e base de sua teoria o pensamento de Karl Marx e Frederick Engels. A concepção educacional que será inaugurada com Gramsci, situando-a na superestrutura, é parte conjunta da concepção econômica-político-filosófica desses pensadores, de tal modo que os conceitos fundamentais para a compreensão da filosofia gramsciana estão intimamente relacionados às categorias apresentadas por Marx e Engels.

Conforme aponta Manacorda (2010, p. 39), nos escritos conhecidos de Marx e Engels há textos - embora não muito numerosos - de cunho pedagógico, que tinham a função de orientação do movimento operário. Esses textos são, eventualmente, programas políticos escritos num intervalo de 30 anos, em momentos determinantes na história da organização da luta do proletariado. 0 primeiro texto, escrito para o surgimento do Partido Comunista, vésperas da revolução de 1848; o segundo, para a primeira Associação Internacional dos Trabalhadores em 1866; e o terceiro texto, para o primeiro Partido Operário Unitário da Alemanha, em $१ ८ 75$.

Com a publicação de 0 Manifesto Comunista, em 1848, Marx e Engels difundem a defesa de uma escola socialista, adequada e vinculada ao mundo do trabalho, onde escola e trabalho são compreendidos de modo complementar, necessário e fundante. Nessa mesma obra, os autores enfatizam a demanda estatal para a educação das crianças, unindo a 
essa premissa a reivindicação da escola pública e gratuita, com um ensino que beneficiasse de modo imediato os sujeitos como finalidade única, possibilitando condições necessárias e favoráveis ao processo da consciência histórica dos sujeitos.

Para Marx, a escola é detentora da responsabilidade de formar os jovens, desenvolvendo suas aptidões, possibilitando a cada sujeito uma formação que não estratificasse e vinculasse os indivíduos a somente uma função no mundo do trabalho. Ao contrário, a escola deveria formá-los para a assimilação de todo um sistema complexo de produção, em que as mudanças dos ramos de produção eram possíveis, tendo em vista que esta formação educacional os liberta da unilateralidade (MANACORDA, 2010, p. 41).

Essa fragmentação, resultante da sociedade de classes, condiciona a desumanização dos sujeitos, a alienação do trabalhador, a divisão entre quem idealiza e quem executa, a exploração e disseminação da dicotomia social que perpassa inteiramente a sociedade do capital. Dessa forma, o ensino com base nos pressupostos pedagógicos elaborados por Marx, direcionam para uma formação que rompe com a unilateralidade dos sujeitos, contraposto ao "desenvolvimento total, completo, multilateral, em todos os sentidos, das faculdades e das forças produtivas, das necessidades e das capacidades da sua satisfação", a que Marx dá o nome de onilateralidade (MANACORDA, 2010, p. 94).

A onilateralidade, presente nos Manuscritos econômicos-filosóficos de 1844 e na Ideologia Alemã de 1845-1846, se contrapõe a alienação humana, propondo um nexo indissociável e recíproco do desenvolvimento onilateral (completo) dos indivíduos e da sociedade. Tal formação só se efetiva concretamente numa realidade onde haja a totalidade das forças produtivas sob o domínio do "desenvolvimento original e livre dos indivíduos na sociedade comunista", dessa maneira, esta também é o fim ao qual se destina a educação na perspectiva gramsciana (MANACORDA, 2010, p. 94-95).

Gramsci assume a responsabilidade de aproximar a perspectiva teórica do marxismo com a educação, sinalizando a cultura como categoria fundante que perpassa transversalmente a tudo e a todos. É no voltar-se para a cultura que, não só expande o marxismo, mas também delineia caminhos concretos a serem seguidos no processo de formação da classe trabalhadora na luta pela transformação social.

Entretanto, Jesus (2005) nos alerta para a necessária vigilância acerca da concepção de escola não formal, difundida na teoria gramsciana, que não só não centraliza a função "do educar", como também se desdobra em várias outras instituições tão responsáveis no processo de formação das consciências, quanto a própria escola formal. Não cabe aqui uma desqualificação da educação formal, ao contrário, esta é instrumento utilíssimo e necessário à formação de uma cultura, tanto na manutenção de hegemonia como em sua substituição. É necessário compreendermos que desta instituição de prática normalizadora e centralizadora 
da educação, Gramsci exalta a teoria ou a ideia da função objetiva daquilo a que se destina a escola, ao mesmo tempo em que descentraliza e condiciona o funcionamento desta num âmbito maior, como questão de prática social (JESUS, 2005, p. 87 ).

Conforme aponta Nosella (1992, p. 13), a teoria escolar gramsciana se desenvolve segundo dois grandes momentos definitivos para o autor: antes do cárcere e no cárcere. Inicialmente, apontaremos quatro momentos, que perpassam a vida e a teoria gramsciana integralmente, ainda em liberdade, às vésperas da Era Mussolini, são eles: a Associação de Cultura, o Ordine Nuovo, os Conselhos de Fábrica, a Escola de Partido, a Escola por Correspondência.

0 primeiro momento, ou primeira escola gramsciana pontuada, conforme Nosella (1992, p. 12), é fomentada no seio da Primeira Grande Guerra (1914-1918), trazendo à tona duas novas forças na luta pela hegemonia mundial, que representavam os extremos ideológicos da burguesia e do proletariado: EUA, com o presidente Wilson e a Rússia com os maximalistas. Dessa maneira, a ltália foi chamada a tomar partidos, optando pela aliança com a Inglaterra, França e América. É nesse contexto, e com a incoerente posição "neutra" do Partido Socialista Italiano (PSI), que Gramsci e outros intelectuais passaram a assumir uma posição contrária ao partido, o que posteriormente resultaria num artigo polêmico intitulado "Neutralidade ativa e operante".

Ainda em 1917, Gramsci ainda vinculado ao PSI, funda a Associação de Cultura, que se destinava aos proletários de Turim como espaço educativo e de formação política. Com esse espaço formativo, o autor efetiva a concepção pedagógica desinteressada, e pontua a crítica ao partido que, segundo ele, somente atentava para a discussão do contexto atual, de modo que não percebia que as dificuldades de compreensão do contexto são resultados de um "negativo fundo cultural" que assola esta classe. Em verdade, essa Associação de Cultura nunca foi consolidada, o máximo que o autor alcançou foi o Clube de Vida Moral que agregava amigos e simpatizantes da luta socialista e que por fim permaneceu ativo por poucos meses (NOSELLA, 1992, p. 27).

Com o fim da Grande Guerra e o fortalecimento dos ideais socialistas, o PSI cresce e se fortalece, mesmo sem ter um plano de ação concreta para um processo de insurreição política da classe trabalhadora. Ainda nessa perspectiva de tentar fortalecer o vínculo entre - PSI e o proletariado italiano, Gramsci juntamente com Tasca, Togliatti e Terracini, criam uma revista de circulação semanal chamada Ordine Nuovo. É nessa revista que Gramsci publicará importantes artigos acerca de sua concepção de educação que partia da "elaboração de uma proposta de política nacional efetiva e revolucionária" fomentada no interior dos conselhos de fábrica, nos sindicatos e nos partidos (NOSELLA, 1992, p. 31-32).

Conforme apresenta Manacorda (2013, p. 31-32), Gramsci assume, durante esse período, uma postura prática e positiva acerca dos "temas da organização da cultura", 
passando da "crítica negativa da escola burguesa e da política socialista" e direcionando sua atenção e atividades na busca de "realizações positivas", como por exemplo o socialismo russo. É também percebido acerca do pensamento gramsciano, desse período, uma "nova dimensão internacional" que será não só espacial, mas também temporal, em que por meio desta "o homem da província, o meridional, o historiador, apaixonadamente mergulhado nas tradições, será depois capaz de desenvolver um discurso pedagógico moderno."

Em 1916, Gramsci afirma que a escola é um organismo genuinamente burguês. Em 1919 em texto publicado no Ordine Nuovo, o autor remonta essa tese e afirma que não podemos mais manter a justificativa de uma escola controlada pela classe burguesa, com vistas no seu ideal. Dessa maneira, Manacorda (2013, p. 42) afirma que:

Se, de fato, a burguesia possuísse e buscasse um programa escolar próprio, a escola seria uma coisa viva; ao contrário, é uma escola de que a burguesia, como classe que controla o Estado, se desinteressa, deixando-a entregue a seus tacanhos burocratas [...] Não há nada a fazer com essa velha estrutura; não sem uma ponta de extremismo maximalista, ele declara agora inútil todo estudo técnico do problema escolar, um puro exercício do enxadrismo mental' em tal situação política, refugiando-se, então, no Estado dos Concelhos, a escola representará uma das atividades políticas mais importantes e essenciais, e a geração hodierna nela será educada na prática da disciplina social necessária para agir na sociedade comunista.

Os Cadernos do Cárcere compõem parte significativa da teoria gramsciana, assumindo um valor simbólico de resistência por ter sido integralmente elaborada entre 8 de fevereiro de 1929 e agosto de 1935, período que corresponde ao encarceramento do autor que só finalizará meses antes de sua morte em abril de 1937. Os Cadernos somam um total de 33 escritos, em que quatro destes são exercícios de tradução e todos os outros abrangem o projeto científico fur ewig, assinalado por Gramsci em carta a sua cunhada Tatiana Schucht, que posteriormente responsabilizou-se em enumerar as 33 obras do preso político de Turim.

Acerca da expressão fur ewig traduzida como "para sempre", Nosella (1992, p. 103) afirma que esta perspectiva, endossa o princípio "desinteressado" no qual tanto Gramsci fez alusão, com vistas à uma prática, exercida pelo autor, que dialogasse com a necessária função dos intelectuais na vida italiana. 0 "para sempre" desinteressado, parte do pressuposto de não ser imediatamente motivado, subjetivo e individual, "mas de longo alcance e que interessa objetivamente a muitos homens na história."

A educação é trabalhada nos textos gramscianos a partir do Caderno 1, mas é com as correspondências endereçadas à família e tendo como motivação a educação dos dois filhos que o autor direciona a crítica ao espontaneísmo, que tem como princípio uma concepção metafísica de educação, partindo da pressuposição de que cada criança carrega, 
em potência, um adulto, necessitando somente do direcionamento ajustado para desenvolverse o que, em estado latente, já o envolve (META, 2017, p. 232).

Acerca da compreensão do processo educativo, Gramsci ressalta a necessidade de uma concepção histórica dos sujeitos, rejeitando dessa maneira toda a tradição iluminista de educação que "considera o ensino como um processo voltado a 'desenovelar' presumidas qualidades inatas na consciência da criança." 0 que Gramsci intentava com a negação do modelo educacional espontaneísta era demonstrar que o velho e o novo - o passado e o presente fundidos num só movimento de vida e de história, se encontram também na prática educativa, de modo que toda geração anterior, educa e forma a nova geração, de modo que a educação "é a luta contra os instintos ligados às funções biológicas elementares, uma luta contra a natureza, a fim de dominá-la e criar" sujeitos conforme seu tempo (META, 2017, p. 232).

Gramsci compreende a escola, não sob a ótica abstrata de sua função pensada de forma isolada. Ao contrário, ele parte da relação integrante de que a escola, enquanto aparelho do Estado, ocupa um dos muitos espaços relativos à educação da sociedade, sendo reconhecida enquanto "agência educativa complexa", que mantém com outras estruturas sociais uma relação necessária para poder exercer sua função (META, 2017, p. 232).

A questão escolar, em Gramsci, é despontada por via da discussão dos intelectuais e sua função no processo de "intelectualização da atividade prática e da praticização da atividade teórica." Dessa maneira, o autor constrói um caminho investigativo acerca dos "modos concretos segundo os quais essa escola poderá se configurar." (MANACORDA, 2013, p. 177-178).

É nos escritos sobre educação, e tomando como ponto de referência as escolas soviéticas, que o autor aprofunda a crítica à fragmentação do ensino em ensino humanista e ensino técnico, pontuando que estes assumem, dentro de uma sociedade de classes, através da dicotomia trabalho-escola, a garantia da manutenção desta, e a fomentação da distinção social e exploração do trabalho. Dessa maneira, a escola lessa é a escola da modernidade) dividiu-se em escola para os que pensam e escola para os que fazem, ou seja, cada atividade prática cria escola para seus dirigentes e especialistas e, consequentemente, tende a "criar um grupo de intelectuais" que passariam a lecionar nessas mesmas escolas (META, 2017, p. 246).

Com essa tônica revolucionária e sem jamais perder o foco de sua linha política de ação (preparar os quadros dirigentes para governar o novo Estado Proletário), Gramsci defende o projeto pedagógico da Escola Desinteressada. Opondo-se a Gentile, que parte

4 Intelectual contemporâneo de Gramsci, recorrentemente criticado pelo autor, devido sua concepção pedagógica "vislumbrar os resultados de um hegelianismo fechado e impenetrável às e pelas dinâmicas dialéticas da história e, portanto, assimiláveis [...] ao evolucionismo e ao determinismo." (D'ANNA, 2017, p. 334). 
do pressuposto de que na escola só deveriam frequentar aqueles que buscam "a cultura pela cultura" e, dessa maneira, idealiza uma reforma escolar para a Itália no período de 1918, estendendo esse debate por muito tempo, numa constante reformulação da escola profissional e da cultura geral, ou seja, a escola do saber interessado.

A Escola Desinteressada é para além de uma oposição filológica, uma proposta ideológica, política, que defende que "no modo de produção socialista a escola não deveria ser imediatamente interessada", pois a esta somente importa a formação de uma minoria privilegiada. Segundo Nosella (1992, p. 57), essas terminologias - interessado e desinteressado - se opõem na medida que esta segunda tem como proposta o princípio pedagógico de amplo alcance, que não se destina à formação de uma classe, mas de todos, da coletividade e da humanidade inteira.

Após a defesa da escola desinteressada, Gramsci defende para a escola socialista, um princípio único ou unitário que pautava a concepção de formação profissional e humanista, ampliando e transformando a relação entre o trabalho industrial e o trabalho intelectual em todas as instâncias da sociedade, sem limitar-se somente a instituição escolar.

A onilateralidade, enquanto princípio norteador de uma formação escolar, era, conforme defendia Gramsci, necessária aos tempos modernos, tendo em vista o desenvolvimento das forças produtivas que exigia da classe trabalhadora a especialização técnica, e esta formação, unida à ideia da formação humana, é, para o autor, o instrumento necessário para criação de novas relações entre $\circ$ trabalho intelectual e o trabalho industrial e que certamente tenderia à abrangência de todas as gerações, classes e grupos (GRAMSCl, 2001, p. 33).

Gramsci estruturou uma concepção pedagógica original, que era dividida em quatro níveis, tomando como base "seus conteúdos e métodos de ensino, mas também com referência à disposição da carreira escolar". Inspirado no modelo clássico de escolas na Itália (elementar, ginásio, liceu e universidade), o autor configura uma escola estruturalmente diferente, com seus níveis adequados ao desenvolvimento psicológico de cada sujeito, visando o real objetivo: "a inserção e orientação dos jovens, dotados de uma certa autonomia intelectual e de uma capacidade intelectual e prática ao mesmo tempo, e de orientação independente." (GRAMSCl, 2011, p. 215).

Ao tratar dos conteúdos e dos métodos de ensino, a escola elementar destinaria seu processo formativo para a "nova concepção do mundo" que, contrária a concepção tradicional, pautava-se na formação dos sujeitos com base nas primeiras noções de direitos e deveres, Estado e Sociedade, em conjunto aos hábitos de leitura e escrita, matemática e noções de geografia e história. Acerca dessa terminologia "nova concepção do mundo", Manacorda (2013, p. 216) nos atenta para a polemização de alguns termos no contexto de 
repressão que Gramsci viveu, de modo que "nova", quando equivalente à "nova ordem", "nova sociedade", é rodeado de significações correlacionadas ao socialismo e ao marxismo.

Com duração entre nove ou dez anos, a Escola Única seria dividida em três ou quatro anos para a formação elementar, o ginásio duraria dois anos assim como o liceu, o que equivaleria à inserção com seis anos e formação escolar completa aos dezesseis, assim como observou na União Soviética. 0 liceu, correspondente ao nível escolar destinado aos jovens é apontado por Gramsci como fase fundamental no processo educativo dessa escola, posto que, nessa etapa que é difundida com tamanho vigor os princípios humanistas da "autodisciplina intelectual e autonomia moral" fundamentais para o processo seguinte de formação seja, no campo intelectual ou no campo profissional. Nesse nível, prioritariamente, as atividades serão desenvolvidas nas bibliotecas, em seminários, nos laboratórios, buscando abranger o princípio da educação profissional. Conforme aponta Manacorda (2013, p. 183):

Gramsci propõe, portanto, dois níveis metodologicamente bem distintos da escola única: o primeiro, simplesmente ativo; mas propriamente criativo, o segundo, de preparação para o estudo universitário; e acena novamente à orientação profissional, já mencionada ao falar, no início, da perspectiva de uma escola unitária, assunto para o qual se voltará em seguida.

Nesse ponto, ao afirmar uma proposta pedagógica que aparentemente é percebida como dupla, Gramsci afirma que a distinção entre a escola criativa e a escola ativa é em verdade um processo de transição de uma à outra, ou seja, "toda escola unitária é escola ativa, ao passo que a escola criativa é uma fase, a coroação da escola ativa" que, segundo Manacorda (2013), é a consolidação do "abandono do espontaneísmo" e criação de uma nova concepção de espontaneísmo atrelado ao ativismo (GRAMSCI, 2011, p. 218).

\footnotetext{
Aqui ele acena para uma definição 'clássica' também da escola criativa, que não é uma escola de "interventores e descobridores', mas uma escola em que a 'recepção' - este é o ermo recorrente nessas notas; depois dirá 'aprendizagem' - ocorre 'por meio de um esforço espontâneo e autônomo do aluno', enquanto o professor exerce uma função de controle e de orientação amigável, como ocorre ou deveria ocorrer na universidade. (MANACORDA, 2013, p. १८३).
}

É no Q12 que Gramsci tratará pontualmente da função que o mestre tem na sociedade, reforçando sua importância dentro da escola assumindo a função de mediador entre a sociedade e seus alunos. Conforme afirma Jesus (2005), em Gramsci, a relação mestre-aluno deveria ser democrática e a distinção entre um e outro dentro do espaço educativo, corresponde efetivamente à consciência - concepção do mundo - do mestre com relação distintas realidades em que cada um está inserido, ou seja, este deve ser "consciente 
do contraste entre o tipo de sociedade e cultura que ele representa e o tipo de sociedade e cultura representada pelo aluno." (JESUS, 2005, p. 78-79).

A consciência da função social da prática educativa é fundamento principal para distinção entre mestre e o professor, onde o primeiro necessariamente comprometese na formação dos indivíduos, mediando o caminho entre os conhecimentos historicamente acumulados e vinculando esses no campo prático das relações sociais, e isso, viabiliza-se pelo estímulo do desenvolvimento da personalidade de cada um na busca pela autonomia social.

\section{PRINCÍPIO EDUCATIUO COMO PRINCÍPIO PARA O ENSINO DA FILOSOFIA}

Ao vincularmos o pensamento de Gramsci com uma prática de ensino específica, no caso aqui, a filosofia, é salutar retornarmos recorrentemente às concepções de educação, de escola e em específico de ensino defendidas pelo autor. Nesse estudo, a concepção de escola dialoga com a Escola Única e Desinteressada de Gramsci, reiterando a função escolar de garantir uma relação orgânica entre cultura e trabalho, partindo da noção de aprimoramento da concepção do mundo dos sujeitos, rompendo com os limites do senso comum, desenvolvendo nestes uma nova concepção, agora histórica, dialética e do mundo (GRAMSCl, 2001, p. 43).

0 processo de ensino e aprendizagem não é abordado pelo autor de modo evidente e com tal terminologia, mas é exposto em trechos do Caderno 2, correlacionado ao tema "escola", desdobrando-se em observações acerca das reformulações dos métodos, necessárias e fundantes na edificação da Escola Única e Desinteressada.

Silveira (2013, p. 63) aponta que, na formação escolar, conforme defendia Gramsci, o método de ensino é o ponto primeiro a ser reconfigurado no que tange a proposta da escola desinteressada. 0 método tradicional, pautado na transmissão de conhecimentos, no domínio dos conteúdos curriculares não é descartado por Gramsci, ao contrário, estes conteúdos são necessários para a formação, fazendo-se necessário à ênfase na formação da "autodisciplina intelectual e a autonomia moral", imperativas pra qualquer campo de atuação que os estudantes escolham a posteriori na vida escolar, seja na universidade (caráter científico), seja na indústria, no comércio (caráter prático-produtivo).

É pertinente que ao refletirmos sobre as contribuições da teoria gramsciana para o ensino de filosofia, ponderemos sobre noções de Filosofia enquanto concepção epistemológica/ontológica do sujeito professor - que se constitui nos seus processos de formação, nas suas escolhas por afinidades teóricas-filosóficas - mas também enquanto 
componente curricular nos espaços educacionais. Ambas abordagens acionam campos ideológicos - seja enquanto concepção do mundo do docente, seja como campo conceitual da história da filosofia - os limites de intersecção de ambas perspectivas perpassam as experiências de ensinar e aprender temas e questões vivenciados na sala de aula.

Ao relacionar o princípio pedagógico de Gramsci e o ensino de filosofia na educação básica, Silveira (2013, p. 64) parte de três indagações para fundamentar seu argumento e que são significativas para a nossa proposta de análise.

\footnotetext{
$\left.1^{\circ}\right)$ Pode a escola, instituição planejada para atender às necessidades do capitalismo, formar cidadãos nessa perspectiva e com esse perfil, pensado por Gramsci?

$2^{\circ}$ ) Caso possa, de que forma ela o faria?

$\left.3^{\circ}\right)$ Que contribuições específicas a Filosofia, como componente curricular do Ensino Médio, poderia oferecer para esta formação?
}

Com base na teoria gramsciana, compreendemos que a escola, com todas as limitações impostas pelas exigências do capital, ao agir como mediadora no processo de formação de uma nova concepção de mundo e de cidadania, está formando uma nova cultura, um novo cidadão e uma nova cidadã.

A função de mediação é viabilizada na elaboração de uma concepção do mundo crítica vinculada ao agir consciente e ao processo de transformação social. Essa mediação é concretizada na prática pedagógica, no processo de ensinar e aprender, onde a "transmissão/socialização de conteúdo é essencial para que a escola contribua para esse objetivo." (SILVEIRA, 2013, p. 67).

A segunda problemática retoma os métodos da escola desinteressada proposta por Gramsci, onde se propõe que a educação comporte um ensino sem direcionamento efetivo para um campo específico do mundo do trabalho, ou seja, a escola desinteressada forma as/os cidadãos, partindo da necessidade de fomentar nestes a relação com o pensamento, com a direção; a escola formando e garantindo conhecimento suficiente à todas e todos para assumirem o papel de dirigentes.

A terceira indagação que Silveira (2013) nos aponta pode facilmente ser respondida à luz da seguinte afirmação de Gramsci no $Q$ १:

Criar uma nova cultura não significa apenas fazer individualmente descobertas 'originais'; significa também, e, sobretudo, difundir criticamente verdades já descobertas, 'socializá-las' por assim dizer; e, portanto, transformá-las em base de ações vitais, em elemento de coordenação e de ordem intelectual e moral. 0 fato de que uma multidão de homens 
seja conduzida a pensar coerentemente e de maneira unitária a realidade presente é um fato 'filosófico' bem mais importante e 'original' do que a descoberta, por parte de um 'gênio' filosófico, de uma nova verdade que permaneça como patrimônio de pequenos grupos intelectuais. (GRAMSCl, 2001, p. 95).

Compreendendo que a afirmação acima incita uma crítica à uma tradição filosófica pautada na negação da realidade social como locus de produção e disseminação da filosofia, Gramsci provoca uma cisão na história do pensamento ao negar a serventia da filosofia enquanto conhecimento de poucos, defendendo seu caráter social e formativo. A escola, enquanto espaço de práticas sociais, possibilita o deslocar da Filosofia enquanto conhecimento de alguns, para conhecimento criador de novas culturas e formador das consciências.

A criação de uma nova cultura também se dá no âmbito da escola, na relação com o professor/professora enquanto intelectual fomentando o campo da formação e elevação cultural dos/das estudantes. Pensar a escola, segundo Gramsci é, antes de tudo, construir um caminho que viabilize o processo de ensino e aprendizagem, com base no diálogo e reflexão crítica, histórica, social, política, econômica e cultural.

A filosofia da práxis é, então, o ponto culminante no processo de transformação social, pois a filosofia separada da teoria da história e da política é metafísica, restrita meramente a interpretações. É o elo fundante entre o princípio pedagógico de Gramsci e a prática do ensino de filosofia; esse elo pressupõe a correlação dialética e necessária da teoria e da prática, unificando e viabilizando um caminho mais crítico para o processo de formação de uma nova cultura com vistas a concepções de mundo mais críticas e atuantes, o que inclui um projeto político que considere a escola enquanto instrumento ideológico da superestrutura.

Gramsci analisa da tese Xl, enquanto desenho original da concepção marxista de filosofia da práxis, apontando que nesta trata-se da "historicidade da filosofia", denunciando a "filosofia absoluta ou especulativa" que se fundamenta, exclusivamente, a partir da concepção abstrata de mundo, mantendo-se alheia à história, às relações sociais, à cultura, à vida prática dos sujeitos históricos. Não diferente do autor, propomos que a mesma tese fomente provocações, reflexões sobre importância da prática educativa e a teoria filosófica implicadas na realidade objetiva do espaço escolar enquanto espaço do pensamento filosófico (GRAMSCl, 1999, p. 340). 


\section{CONSIDERAÇÕES FINAIS}

Dialogar o ensino de filosofia no ensino médio com o princípio educativo de Gramsci no atual contexto educacional, é enfatizar a defesa por uma educação pública que forme jovens críticos e ativos para a experiência da cidadania, tendo como pressuposto a superação da condição de subalternidade cultural, social, política e econômica.

A pungência de retomar os escritos de Gramsci sobre a educação, possibilita enfatizar a formação onilateral na escola unitária como inspiração para um ensino de filosofia, quiçá de uma educação básica, que tenha como horizonte a socialização dos conteúdos historicamente acumulados, mas também a formação de uma cultura reflexiva, crítica de cidadãs e cidadãos engajados na construção de uma contra-hegemonia.

Ao levarmos em consideração a educação nacional, mesmo que engessada no molde capitalista, atentemos para as mudanças que vem se consolidando tão repentinamente na última década. No que tange ao ensino de filosofia propriamente dito, mas não de maneira isolada, reformas foram consolidadas e trouxeram à tona a mesma problemática já referendada neste trabalho: a necessidade ou não do ensino de filosofia nas escolas brasileiras.

Conforme aponta Nosella (2015, p. 198), "sabemos que não existe, na concretude, nem o puramente teórico, nem o puramente prático; assim como não existem percursos formativos exclusivamente desinteressados, humanistas, e outros exclusivamente utilitários, profissionalizantes." No entanto, o Ensino Médio, conforme vem se configurando nos moldes atuais, tem historicamente abrangido uma única via: a profissionalização imediata de uma classe e a manutenção de outra no controle da hegemonia e reprodução da ideologia neoliberal.

Consideramos que a relação filosofia da práxis e ensino de filosofia não é somente uma apropriação de uma pela outra, mas inclui um projeto político com vista à função da escola enquanto instrumento ideológico da superestrutura, que ao assumir o compromisso de formar cidadãs e cidadãos, deve compreender que tal formação não ocorre longe do campo político. Assim, apontamos que a filosofia da práxis possibilita esse compromisso com o movimento imanente da história e das transformações que os sujeitos operam na história, de ser política e comprometer-se na reelaboração e socialização das verdades já existentes, que até então se mantiveram restrita a grupos seletos destinados à atividade unicamente teórica.

\section{REFERÊNCIAS}

BRASIL. Lei n. 4.024 de 20 de dezembro de 1961. Fixa as Diretrizes e Bases da Educação Nacional. Diário Oficial da União, Brasilia, DF, 14 dez. 1962. Disponível em: http://www.planalto.gov.br/CCivil_03/ LEIS/L4024.htm. Acesso em: 27 jun. 2020. 
BRASIL. Lei n. 5.692 de 11 de agosto de 1971. Fixa as Diretrizes e Bases da Educação Nacional e dá outras providências. Diário Oficial da União, Brasília, DF, 12 ago. 1971. Disponível em: http://www.planalto. gov.br/CCivil_03/LEIS/L4024.htm. Acesso em: 27 jun. 2020.

BRASIL. Lei n. 9.394 de 20 de dezembro de 1996. Estabelece as Diretrizes e Bases da Educação Nacional. Estabelece as diretrizes e bases da educação nacional. Diário Oficial da União, Brasília, DF, 21 dez. 1996. Disponível em: http://www.planalto.gov.br/ccivil_03/leis/L9394.htm. Acesso em: 27 jun. 2020.

BRASIL. Lei $n$. 11.684 de 02 de junho de 2008. Altera o art. 36 da Lei n 9.394, de 20 de dezembro de 1996, que estabelece as diretrizes e bases da educação nacional, para incluir a Filosofia e a Sociologia como disciplinas obrigatórias nos currículos do ensino médio. Diário Oficial da União, Brasilia, DF, 3 jul. 2008. Disponivel em: http://www.planalto.gov.br/ccivil_03/_Ato2007-2010/2008/Lei/L11684. htm. Acesso em: 27 jun. 2020.

D’ANNA. G. Gentile, Giovanni. In: LIGUORI, G.; VOZA, P. Dicionário gramsciano (1926-1937). São Paulo: Boitempo, 2017.

DUARTE, A. M. C. et al. A contrarreforma do Ensino Médio e as perdas de direitos sociais no Brasil. Roteiro, v. 45, p. 1-26, 4 jun. 2020.

GRAMSCI, A. Cadernos do cárcere. Edição e tradução: Carlos Nelson Coutinho. Rio de Janeiro: Civilização brasileira, 1999. v. 1.

GRAMSCl, A. Cadernos do cárcere. Edição e tradução: Carlos Nelson Coutinho. Rio de Janeiro: Civilização brasileira, 2001. v. 2.

GRAMSCl, A. 0 leitor de Gramsci: escritos escolhidos 1916-1935. Organização: Carlos Nelson Coutinho. Rio de Janeiro: Civilização Brasileira, 2011.

JESUS, A. T. 0 pensamento e a prática escolar de Gramsci. 2. ed. Campinas, SP: Autores Associados, 2005.

MANACORDA, M. A. Marx e a pedagogia moderna. Campinas, SP: Editora Alínea, 2010.

MANACORDA, M. A. 0 princípio educativo em Gramsci: americanismo e conformismo. Campinas, SP: Editora Alínea, 2013.

MARX, K.; ENGELS F. Teses sobre Feuerbach In: MARX, K.; ENGELS F. A ideologia alemã: crítica da mais recente filosofia alemã em seus representantes Feuerbach, B. Bauer e Stirner, e do socialismo alemão em seus diferentes profetas (1845-1846). Tradução: Rubens Enderle, Nélio Schneider e Luciano Cavini Martoano. São Paulo: Boitempo, 2007.

META, C. Educação. In: LIGUORI, G.; VOZA, P. Dicionário gramsciano (1926-1937). São Paulo: Boitempo, 2017. 
NOSELLA, P. A escola de Gramsci. São Paulo: Cortez, 1992.

NOSELLA, P. A escola de Gramsci: vinte e dois anos depois. Revista Trabalho Necessário, ano 13, n. 20, p. 172-205, 2015.

SILVEIRA, R. Ensino de filosofia e cidadania: uma abordagem a partir de Gramsci. Revista Brasileira de Estudos Pedagógicos, v. 94, p. 53-77, 2013.

Endereço para correspondência: Rua Severino Ramos Lins, 182, Castelo Branco, 58050-540, João Pessoa, Paraiba, Brasil; gncarreiro@gmail.com 
